\section{(6) OPEN ACCESS}

\title{
Distinct aetiopathogenesis in subgroups of functional dyspepsia according to the Rome III criteria
}

\author{
Yu-Jen Fang, ${ }^{1}$ Jyh-Ming Liou, ${ }^{2}$ Chieh-Chang Chen, ${ }^{1,2}$ Ji-Yuh Lee, ${ }^{1}$ Yao-Chun Hsu, ${ }^{3}$ \\ Mei-Jyh Chen, ${ }^{2}$ Ping-Huei Tseng, ${ }^{2}$ Chien-Chuan Chen, ${ }^{2}$ Chi-Yang Chang, ${ }^{3}$ \\ Tsung-Hua Yang, ${ }^{1}$ Wen-Hsiung Chang, ${ }^{4}$ Jeng-Yi Wu, ${ }^{5}$ Hsiu-Po Wang, ${ }^{2}$ \\ Jiing-Chyuan Luo, ${ }^{6}$ Jaw-Town Lin, ${ }^{2,7}$ Chia-Tung Shun, ${ }^{8}$ Ming-Shiang Wu, ${ }^{2}$ for the \\ Taiwan Gastrointestinal Disease and Helicobacter Consortium
}

\begin{abstract}
- Additional material is published online only. To view please visit the journal online (http://dx.doi.org/10.1136/ gutjnl-2014-308114)

For numbered affiliations see end of article.

\section{Correspondence to} Professor Ming-Shiang Wu, Department of Internal Medicine and Primary Care Medicine, National Taiwan University Hospital, National Taiwan University, College of Medicine, No. 7, Chung-Shan S. Road, Taipei 100, Taiwan: mingshiang@ntu.edu.tw and
\end{abstract}

010002@ntuh.gov.tw

J-ML and M-SW contributed equally.

Received 25 July 2014 Revised 8 October 2014 Accepted 18 October 2014 Published Online First 18 November 2014

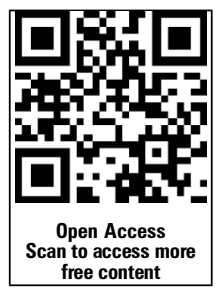

CrossMark

\footnotetext{
To cite: Fang Y-J, Liou J-M, Chen C-C, et al. Gut 2015;64:1517-1528.
}

\section{ABSTRACT}

Background and objective Whether there is distinct pathogenesis in subgroups of functional dyspepsia (FD), the postprandial distress syndrome (PDS) and epigastric pain syndrome (EPS) remains controversial. We aimed to identify the risk factors of FD and its subgroups in the Chinese population.

Methods Patients with dyspepsia and healthy subjects who underwent gastric cancer screening were enrolled in this multicentre study from 2010 to 2012. All patients were evaluated by questionnaire, oesophagoduodenoscopy, histological examination and Helicobacter pylori tests. Subgroups of FD were classified according to the Rome III criteria. Psychiatric stress was assessed by the short form Brief Symptom Rating Scale. CagA and VacA genotypes were determined by PCR.

Results 0 2378 patients screened for eligibility, 771 and 491 fulfilled the diagnostic criteria of uninvestigated dyspepsia and FD, respectively. $298(60.7 \%)$ and 353 $(71.9 \%)$ individuals were diagnosed with EPS and PDS, respectively, whereas 169 (34.4\%) had the overlap syndrome. As compared with 1031 healthy controls, PDS and EPS shared some common risk factors, including younger age (OR $0.95 ; 99.5 \% \mathrm{Cl} 0.93$ to 0.98$)$, nonsteroidal anti-inflammatory drugs (OR 6.60; 99.5\% Cl 3.13 to 13.90$)$, anxiety (OR $3.41 ; 99.5 \% \mathrm{Cl} 2.01$ to 5.77 ) and concomitant IBS (OR 6.89; $99.5 \% \mathrm{Cl} 3.41$ to 13.94). By contrast, H. pylori (OR 1.86; $99.5 \% \mathrm{Cl} 1.01$ to 3.45$)$, unmarried status (OR $4.22 ; 99.5 \% \mathrm{Cl} 2.02$ to 8.81 ), sleep disturbance (OR 2.56; $99.5 \% \mathrm{Cl} 1.29$ to 5.07 ) and depression (OR 2.34; 99.5\% Cl 1.04 to 5.36) were associated with PDS. Moderate to severe antral atrophy and CagA positive strains were also more prevalent in PDS. Conclusions Different risk factors exist among FD subgroups based on the Rome III criteria, indicating distinct aetiopathogenesis of the subdivisions that may necessitate different therapeutic strategies.

\section{INTRODUCTION}

Functional dyspepsia (FD), a common but heterogeneous disease, remains a great burden to the healthcare system. ${ }^{1-5}$ Numerous pathophysiological mechanisms, such as delayed gastric emptying, impaired gastric accommodation to a meal, ${ }^{67}$ visceral hypersensitivity to gastric distension, ${ }^{8}{ }^{9}$ Helicobacter pylori infection, ${ }^{10-13}$ psychosocial factors and central nervous system dysfunction, ${ }^{14-16}$

\section{Significance of this study}

What is already known on this subject?

- Functional dyspepsia (FD) is heterogeneous in its aetiology, pathogenesis and treatment responses.

- FD has been subdivided into epigastric pain syndrome (EPS) and postprandial distress syndrome (PDS) by the Rome III Consensus in an attempt to guide therapy.

- The subdivision was based on post hoc analysis and warrants more clinical data from different ethnic populations to support the distinct aetiopathogenesis of the two subgroups.

What are the new findings?

- PDS and EPS shared some common risk factors including younger age, non-steroidal anti-inflammatory drugs, anxiety and concomitant IBS.

- H. pylori, unmarried status, sleep disturbance, depression, and less coffee consumption were associated with PDS, but not with EPS.

- The association of $H$. pylori with PDS was probably attributed to the more severe gastric atrophy at the antrum and the higher prevalence of CagA positive $H$. pylori strains.

How might it impact on clinical practice in the foreseeable future?

- Different risk factors exist for subgroups of FD based on the Rome III criteria, indicating the distinct aetiopathogenesis of the subdivisions of FD that might necessitate different therapeutic strategies. and lifestyle factors have been shown to be involved in the pathogenesis of FD. ${ }^{17-20}$ Due to its complexity in pathogenesis, treatment for FD remains a challenge in clinical practice. ${ }^{2} 42122$ Although several treatment strategies, including testing and treatment for H. pylori, use of proton pump inhibitors, prokinetic agents and antidepressants have been shown to be effective in FD, each strategy is only effective in a small proportion of patients with FD. ${ }^{2} 42122$ 
In order to simplify the intricate heterogeneity of this symptom complex and to guide the treatment, the Rome III Consensus proposed the subdivision of FD into two subgroups: the epigastric pain syndrome (EPS) which is characterised by epigastric pain and burning, and the postprandial distress syndrome (PDS) which is characterised by postprandial fullness and early satiety. ${ }^{1}{ }^{4}$ However, the subdivision of EPS and PDS was based on post hoc factor analysis of epidemiologic and pathophysiologic studies that used the Rome II definition without direct supporting scientific evidence. ${ }^{14}$ Therefore, it is crucial to elucidate whether there are distinct aetiologies and pathogenesis underlying the two subdivisions.

However, relatively few studies have investigated the differential pathogenesis in subgroups of FD according to the Rome III definition. $^{23-29}$ Increased recruitment of eosinophils in the duodenum has been observed in patients with PDS, but not EPS, in several studies. ${ }^{4} 2324$ Shindo et al ${ }^{25}$ showed that lower acylated ghrelin levels might result in delayed gastric emptying in patients with PDS, but not with EPS. By contrast, Haag et al ${ }^{26}$ reported no difference in delayed gastric emptying between PDS and EPS, while Kusano $e t a l^{27}$ showed rapid gastric emptying in PDS. Although previous epidemiological studies and meta-analysis of randomised trials supported the association of H. pylori with FD, whether it has differential roles in EPS and PDS remains poorly understood. ${ }^{10-13}$ Besides, few studies addressed the impact of severity of gastric inflammation in the EPS and PDS subgroups. ${ }^{13} 28$ Recently, distinct psychopathological and personality traits have been reported in patients with PDS and EPS. ${ }^{14}{ }^{15}$ Aro et $a l^{14}$ showed differential associations of anxiety with PDS, but not with EPS. We previously identified that PDS, but not EPS, was independently associated with psychopathological stress, specifically in somatisation, depression and phobia. ${ }^{15}$ Nevertheless, we did not recruit healthy controls and were therefore not able to confirm the association of psychopathology with FD as a whole in that study. ${ }^{15}$ Furthermore, we did not assess the role of $H$. pylori in FD. ${ }^{15}$

Accordingly, in the present study we aimed to comprehensively explore the pathophysiological mechanisms, including psychopathology traits, $H$. pylori infection, virulence genotypes of $H$. pylori, severity of gastric inflammation and lifestyle factors underlying the two distinct subgroup syndromes of FD.

\section{MATERIALS AND METHODS}

\section{Setting and study subjects}

This multicentre, prospective study was conducted at the National Taiwan University Hospital (NTUH) in northern Taiwan and its Yun-Lin Branch in mid-west Taiwan from January 2010 to May 2012. Although these two hospitals were referral centres in these two regions, patients can visit the two centres as open access clinics without referral from primary care physicians. Consecutive adult patients with dyspeptic symptoms at outpatient clinics were invited to be assessed with the standard Rome III diagnostic questionnaire. Consecutive asymptomatic subjects who underwent gastric cancer screening in the two hospitals were enrolled as healthy controls. All patients and controls underwent detailed history taking, including demographic data, lifestyle factors, and the 5-item Brief Symptom Rating Scale (BSRS-5), a validated short form of the BSRS for the evaluation of psychiatric distress and personality traits. ${ }^{30}$ They also underwent oesophagogastroduodenoscopy (OGD) and laboratory check-up to exclude organic disease or other metabolic disorders. All subjects with the following conditions were excluded: (1) age less than 20 years; (2) presence of organic disorders such as ulcers (defined as mucosal defect of $3 \mathrm{~mm}$ or greater), ulcer scar, erosive oesophagitis, Barrett's oesophagus and malignancy on OGD survey (however, patients with erosions (defined as mucosal defect less than $3 \mathrm{~mm}$ ) were not excluded); (3) concurrent severe illness, including malignancy at any sites, diabetes mellitus, advanced chronic kidney disease, liver cirrhosis and porphyria; (4) history of abdominal surgery; (5) bleeding tendency or current use of anticoagulants; and (6) regular use of aspirin, non-steroidal anti-inflammatory drugs (NSAIDs) or proton pump inhibitors (PPI) for more than 1 month. The study protocol was approved by the institutional review boards of NTUH. Written informed consent was obtained from all patients prior to enrolment.

\section{Rome III diagnostic questionnaire and symptoms definition}

The Chinese version of the questionnaire was translated from the original Rome III FD module. It was reviewed by three investigators (YCH, JML and MSW), and scrutinised by two native Chinese speakers without medical background to confirm the fidelity of translation and to ensure that the text was easy to read and understand. ${ }^{15}$ Details of this questionnaire were described in our previous study. ${ }^{15}$ In brief, the questionnaire consists of 18 questions, which allows the diagnosis of FD and its two subgroups, PDS and EPS, which may coexist by definition. FD was defined as the presence of postprandial fullness/ early satiation or pain/burning more than once per week, in the last 3 months according to the Rome III criteria. ${ }^{1}$ Patients with typical reflux symptoms (heartburn/acid regurgitation), defined as moderate and which occurred more than 2 days per week, were excluded according to the Rome III criteria. ${ }^{1}$ Patients with endoscopically confirmed erosive oesophagitis were also excluded. Non-prominent reflux symptoms may coexist with dyspeptic symptoms. However, patients fulfilling the criteria for functional disorder of the gallbladder and sphincter of Oddi were excluded. Well trained research assistants interviewed the patients to help them complete the questionnaires. IBS was defined as the presence of abdominal pain or discomfort at least 3 days per month in the last 3 months, associated with at least two of the following bowel habit changes: stool frequency, stool form, or symptoms relieved after defaecation according to the Rome III criteria. ${ }^{1}$

\section{Determination $\boldsymbol{H}$. pylori infection, virulence genotypes and severity of gastric inflammation}

All patients underwent serology testing, histological examination, rapid urease test, and culture; the healthy controls underwent the ${ }^{13} \mathrm{C}$-urea breath test $\left({ }^{13} \mathrm{C}\right.$-UBT $)$ to examine H. pylori. Individuals who fulfilled one of the following criteria were defined as having H. pylori infection: (1) a positive ${ }^{13} \mathrm{C}-\mathrm{UBT}$; (2) a positive culture; or (3) at least two positive findings among rapid urease test, histology and serum antibody. The severity of gastritis was graded by the updated Sydney Classification. The CagA gene and the VacA signal region ( $1 / 2)$ and midregion $(\mathrm{m} 1 / 2)$ mosaics were determined by PCR as described previously. ${ }^{31}$

\section{Evaluation of psychiatric distress and lifestyle factors}

BSRS-5 consisted of five parameters-sleep disturbance, anxiety, hostility, depression and inferiority-and was a validated instrument to assess psychiatric distress and personality traits. ${ }^{30}$ The internal consistency coefficients of BSRS-5 ranged from 0.77 to $0.90 .^{30}$ Demographic data and lifestyle factors (including occupation, marital status, blood type, body mass index, education level, exercise habits, vegetarians, medication history, cigarette smoking, and consumption of alcohol, betel nut, tea and coffee were recorded in all patients and controls). Smoking was 
divided into never and ever (including those who are smokers or who quit less 5 years ago). Alcohol drinking was divided into never/rare and regular drinking (more than once a week, and $>40$ g per week). Betel nut chewing was divided into never/rare and regular (including who were chewing or who quit less than 5 years ago). Habits of tea, coffee and exercise were divided into never/rare (less than three times a month) and regular (more than once a week). The different kinds and quantities of tea, coffee and exercise were all noted. We excluded patients who took NSAIDs/aspirin regularly (defined as more than three times per week). We also excluded non-regular users who had taken NSAIDs/aspirin for more than 10 days in the month prior to enrolment. Non-regular users who took NSAIDs/aspirin for less than 10 days in the month prior to enrolment were classified as 'ever' NSAIDs/aspirin recent consumption.

\section{STATISTICAL METHODS}

Categorical data were compared using the $\chi^{2}$ test or Fisher's exact test as appropriate. Continuous data were compared with Student's $t$ test and expressed as mean (SD) or one-way analysis of variance (ANOVA) as appropriate. Logistic regression analysis was used to identify risk factors of uninvestigated dyspepsia, FD and its subgroups, as compared to healthy controls. Adjusted ORs and 95\% CIs were calculated. Those with $\mathrm{p}$ values of less than 0.05 were further included in the multivariable logistic regression models. Multiple testing adjustment with the Holm method was applied for controlling type I error. All statistical tests were two-tailed and $p$ values of less than 0.005 were considered significant after adjustment for multiple testing. Statistical analyses were performed using SPSS V.12.0 for Windows.

\section{RESULTS}

\section{Enrolment of patients with dyspepsia and controls}

During the study period, 2378 patients with dyspeptic symptoms were screened for eligibility (figure 1). Among the 771 individuals who had uninvestigated dyspepsia for more than 3 months, 280 patients (36.3\%) had organic lesions on OGD. Therefore, 491 patients met the diagnostic criteria of FD. Of the 1168 asymptomatic healthy subjects assessed for eligibility, 137 were excluded, because of a history of malignancy in 46 , diabetes mellitus in 86 , chronic kidney diseases in 2 and liver cirrhosis in 3. A total of 1031 asymptomatic healthy subjects were eligible as controls. Among the 491 patients with FD, 298 $(60.7 \%)$ and $353(71.9 \%)$ fulfilled the diagnosis of EPS and PDS, respectively. A total of 169 (34.4\%) had symptoms compatible with both PDS and EPS, whereas $9(1.8 \%)$ patients with FD did not fit the diagnostic criteria of either PDS or EPS. In addition, $124(25.3 \%)$ reported concomitant non-prominent reflux symptoms. The frequency, severity and associated symptoms are summarised in table 1.

We performed logistic regression analysis to explore the risk factors of uninvestigated dyspepsia, FD and its subgroups. The results of univariate analysis are shown in online supplementary tables S1 and S2, whereas the adjusted ORs are presented in tables 2 and 3.

\section{Demographic characteristics among patients with FD and its subgroups}

Women had an increased risk of FD (OR 2.01; 99.5\% CI 1.16 to 3.47) and a slightly higher risk of uninvestigated dyspepsia (OR 1.52; 99.5\% CI 0.98 to 2.38) (table 2). Subgroup analysis showed a trend of increased risk of pure PDS (OR 2.08; 99.5\% CI 0.93 to 4.66), pure EPS (OR 2.26; 99.5\% CI 0.94 to 5.44), and overlap syndrome (OR 2.35; 99.5\% CI 0.92 to 6.04) in women, but the differences were not significant after adjustment for multiple testing (table 3). Those who never married had an increased risk of pure PDS (OR 4.22; 99.5\% CI 2.02 to 8.81) (table 3). Subjects with a higher education level (above college) had a reduced risk of both uninvestigated dyspepsia (OR 0.32; $99.5 \%$ CI 0.17 to 0.60 ) and FD (OR $0.42 ; 99.5 \%$ CI 0.20 to 0.88 ) (table 2). In the subgroup analysis, however, the association remained significant only in the overlap syndrome (OR $0.22 ; 99.5 \%$ CI 0.07 to 0.67 ), but not in pure PDS (OR 0.51; 99.5\% CI 0.17 to 1.56 ) or pure EPS (OR $0.61 ; 99.5 \%$ CI 0.18 to 2.05 ) (table 3).

\section{Lifestyle factors among patients with FD and its subgroups}

Consumption of betel nuts was associated with increased risk of both uninvestigated dyspepsia (OR 6.31; 99.5\% CI 2.20 to 18.12) and FD (OR 4.55; 99.5\% CI 1.30 to 15.91) (table 2). Subgroup analysis showed that betel nut chewing was only associated with the overlap syndrome (OR 6.11; 99.5\% CI 1.24 to 30.22), but not with pure EPS (OR 5.92; 99.5\% CI 0.85 to 41.21) or pure PDS (OR 1.97; 99.5\% CI 0.30 to 12.86) (table 3). Consumption of coffee was associated with a lower risk of uninvestigated dyspepsia (OR $0.65 ; 99.5 \%$ CI 0.44 to 0.97 ) and a trend for an inverse association with FD (OR $0.66 ; 99.5 \%$ CI 0.41 to 1.04 ) (table 2). Subgroup analysis showed that coffee was inversely associated with pure PDS (OR $0.49 ; 99.5 \%$ CI 0.25 to 0.92 ), but not with pure EPS (OR $0.62 ; 99.5 \%$ CI 0.30 to 1.24 ) and overlap syndrome (OR 0.74; 99.5\% CI 0.37 to 1.49 ) (table 3). Regular exercise was associated with a lower risk of uninvestigated dyspepsia (OR $0.51 ; 99.5 \%$ CI 0.35 to 0.74 ) but the association with FD was statistically less significant (OR $0.68 ; 99.5 \%$ CI 0.44 to 1.05 ) (table 2). It was unrelated to any subgroup of FD (table 3). Recent consumption of non-steroidal anti-inflammatory drugs (NSAIDs), but not aspirin, was associated with increased risk of both uninvestigated dyspepsia (OR 5.96; 99.5\% CI 3.04 to 11.69 ) and FD (OR 6.60; 99.5\% CI 3.13 to 13.90 ) (table 2). The associations remained significant for pure PDS (OR 5.30; 99.5\% CI 1.87 to 15.05), pure EPS (OR 7.62; 99.5\% CI 2.77 to 20.95 ) and overlap syndrome (OR 8.76; 99.5\% CI 3.28 to 23.40) (table 3).

\section{Psychopathology and personality traits among patients with FD and its subgroups}

Sleep disturbance was positively associated with both uninvestigated dyspepsia (OR 1.76; 99.5\% CI 1.18 to 2.61 ) and FD (OR $1.72 ; 99.5 \%$ CI 1.09 to 2.73 ) (table 2). Subgroup analysis showed that it was associated with pure PDS (OR 2.56; 99.5\% CI 1.29 to 5.07 ) and overlap syndrome (OR $3.10 ; 99.5 \%$ CI 1.41 to 6.81 ), but not with pure EPS (OR 0.73; 99.5\% CI 0.35 to 1.51 ) (table 3). Anxiety was positively associated with both uninvestigated dyspepsia (OR 2.82; 99.5\% CI 1.78 to 4.46 ) and FD (OR 3.41; 99.5\% CI 2.01 to 5.77) (table 2), as well as different subtypes of FD, including pure PDS (OR 2.80; 99.5\% CI 1.34 to 5.88 ), pure EPS (OR 2.88; 99.5\% CI 1.21 to 6.79 ) and overlap syndrome (OR 4.36; 99.5\% CI 1.84 to 10.34) (table 3). Depression was positively associated with both uninvestigated dyspepsia (OR 1.80; 99.5\% CI 1.10 to 2.93) and FD (OR 1.92; $99.5 \%$ CI 1.10 to 3.33 ) (table 2). Subgroup analysis showed that it was associated with pure PDS (OR 2.34; 99.5\% CI 1.04 to 5.36), but not with pure EPS (OR 1.82; 99.5\% CI 0.74 to 4.49) and overlap syndrome (OR 1.81; $99.5 \%$ CI 0.74 to 4.40 ) (table 3). Hostility was not associated with uninvestigated dyspepsia, FD and its subgroups after multiple testing (tables 2 and 3). Inferiority was inversely associated with FD (OR $0.48 ; 99.5 \%$ CI 
National Taiwan University Hospital (Taipei Medical Center), 1191 Consecutive dyspepsia patients (City-based hospital)

National Taiwan University Hospital, Yu-Lin branch (Yu-Lin Regional Teaching Hospital), 1187 Consecutive dyspepsia patients (Country-based hospital)

\begin{tabular}{|c|c|c|}
\hline $\begin{array}{l}\text { Total of } 165 \\
\text { survey of ga } \\
\text { questionnaire } \\
771 \text { met th } \\
\text { criteria of tl } \\
\text { criteria for } \\
\text { dyspepsia) }\end{array}$ & $\begin{array}{l}\text { completed } \\
\text { rointestinal } \\
\text { (A total of } \\
\text { diagnostic } \\
\text { Rome III } \\
\text { functional }\end{array}$ & $\begin{array}{l}\text { Exclusion Subjects : ( } 723 \text { cases ) } \\
\text { Taipei : } \\
\text { (1) Cancer history : } 25 \text { cases } \\
\text { (2) History of abdominal surgery }: 27 \text { cases } \\
\text { (3) Diabetes mellitus : } 107 \text { cases } \\
\text { (4) Liver cirrhosis : } 8 \text { cases } \\
\text { (5) Chronic kidney disease }: 5 \text { cases } \\
\text { (6) H. pylori eradication therapy }: 86 \text { cases } \\
\text { (7) Refused study }: 57 \text { cases } \\
\text { (8) Regular NASIDs used : } 7 \text { cases, } \\
\text { Regular aspirin used : } 17 \text { cases, } \\
\text { Both NASID and aspirin used }: 1 \text { case } \\
\text { (9) Incomplete questionnaires }: 6 \text { cases } \\
\text { Yu-Lin : }\end{array}$ \\
\hline $\begin{array}{l}\text { All patients receiving } \\
\text { EGD survey and } \\
\text { examination for check } \\
\text { H. pylori status }\end{array}$ & & $\begin{array}{l}\text { (1) Cancer history : } 55 \text { cases } \\
\text { (2) History of abdominal surgery }: 52 \text { cases } \\
\text { (3) Diabetes mellitus : } 149 \text { cases } \\
\text { (4) Liver cirrhosis : } 30 \text { cases } \\
\text { (5) Chronic kidney disease }: 8 \text { cases } \\
\text { (6) H. pylori eradication therapy : } 30 \text { cases } \\
\text { (7) Refused study : } 23 \text { cases }\end{array}$ \\
\hline \multirow{2}{*}{$\begin{array}{l}884 \text { did not meet the } \\
\text { diagnostic criteria of the } \\
\text { Rome III criteria } \\
\text { (1) } 506 \text { ulcer, } 94 \text { ulcer } \\
\text { scar, } 211 \text { reflux } \\
\text { esophagitis, 2Barrett's } \\
\text { esophagus } \\
\text { (2) } 66 \text { gastritis only, or } \\
\text { erosions }\end{array}$} & & $\begin{array}{l}\text { (8) Regular NASIDs used : } 6 \text { cases, } \\
\text { Regular aspirin used : } 16 \text { cases, } \\
\text { (9) Incomplete questionnaires }: 8 \text { cases }\end{array}$ \\
\hline & & $\begin{array}{l}771 \text { met the diagnostic criteria of the Rome } \\
\text { III criteria for functional dyspepsia } \\
\text { (1) } 491 \text { no any systemic lesion, including } \\
184 \text { postprandial distress syndrome, } 129 \\
\text { epigastric pain syndrome, } 169 \text { overlap }\end{array}$ \\
\hline & & $\begin{array}{l}\text { syndrome, } 9 \text { unspecific. } \\
\text { (2)280 with organic lesion, including } 185 \\
\text { ulcer, } 38 \text { ulcer scar, } 57 \text { reflux } \\
\text { esophagitis }\end{array}$ \\
\hline
\end{tabular}

Figure 1 Flowchart of the study.

0.26 to 0.90 ) (table 2). Subgroup analysis found no significant association with any subtype (table 3 ).

\section{H. pylori, virulence genotypes and severity of gastric} inflammation among patients with FD and its subgroups

H. pylori infection was positively associated with both uninvestigated dyspepsia (OR 1.88; 99.5\% CI 1.30 to 2.73 ) and FD (OR $1.60 ; 99.5 \%$ CI 1.03 to 2.48 ) (table 2). Subgroup analysis showed that $H$. pylori infection was associated with only pure PDS (OR 1.86; 99.5\% CI 1.01 to 3.45), but not with pure EPS (OR $1.43 ; 99.5 \%$ CI 0.72 to 2.84 ) or overlap syndrome (OR $1.12 ; 99.5 \%$ CI 0.55 to 2.28 ) (table 3 ). The density of $H$. pylori, severity of intestinal metaplasia, and infiltration of neutrophils and monocytes were not significantly different among the three subgroups (figure 2). However, there was a trend of more moderate and marked gastric atrophy at the antrum in the subgroup of pure PDS (figure 2). Among $H$. pylori infected patients, we observed a trend $(\mathrm{p}=0.044)$ of more CagA positive strains in pure PDS (98.4\%), as compared with pure EPS (89.1\%) and the overlap syndrome $(85.7 \%)$, as shown in table 4 .

\section{Overlap with other functional gastrointestinal disorders}

IBS was significantly associated with uninvestigated dyspepsia (OR 6.09; 99.5\% CI 3.12 to 11.91 ) and FD (OR 6.89; 99.5\% 
Table 1 Symptom frequency, severity of subgroups of functional dyspepsia

\begin{tabular}{|c|c|c|c|c|c|c|c|c|}
\hline \multirow[b]{2}{*}{ Cardinal symptom } & \multicolumn{3}{|c|}{ Pure PDS ( $n=184)$} & \multirow{2}{*}{$\begin{array}{l}\text { Pure EPS } \\
(\mathrm{n}=129) \\
\text { Epigastric pain/ } \\
\text { burning } \\
\mathrm{n}(\%)\end{array}$} & \multicolumn{4}{|c|}{ Pure overlap $(n=169)$} \\
\hline & $\begin{array}{l}\text { Postprandial } \\
\text { fullness } \\
\text { n (\%) }\end{array}$ & $\begin{array}{l}\text { Early } \\
\text { satiation } \\
\mathbf{n}(\%)\end{array}$ & $\begin{array}{l}\text { Both* } \\
\text { n (\%) }\end{array}$ & & $\begin{array}{l}\text { Postprandial } \\
\text { fullness } \\
\mathrm{n}(\%)\end{array}$ & $\begin{array}{l}\text { Early } \\
\text { satiation } \\
\mathrm{n}(\%)\end{array}$ & $\begin{array}{l}\text { Both* } \\
\text { n (\%) }\end{array}$ & $\begin{array}{l}\text { Epigastric pain/burning } \\
\mathrm{n}(\%)\end{array}$ \\
\hline \multicolumn{9}{|l|}{ Frequency } \\
\hline$\geq 2$ days/week & $48(26.1)$ & $40(21.7)$ & $5(2.6)$ & $108(83.7)$ & $53(31.4)$ & $9(5.3)$ & $15(8.9)$ & $86(50.9)$ \\
\hline Every day & $55(29.9)$ & $29(15.7)$ & $7(3.8)$ & $21(16.3)$ & $63(37.3)$ & $12(7.1)$ & $17(10.0)$ & $83(49.1)$ \\
\hline \multicolumn{9}{|l|}{ Severity } \\
\hline Mild & $54(29.3)$ & $29(15.8)$ & $6(3.3)$ & $61(47.3)$ & $39(30.2)$ & $10(5.9)$ & $10(5.9)$ & $58(34.3)$ \\
\hline Moderate & $40(21.7)$ & $21(11.4)$ & $4(2.1)$ & $55(42.6)$ & $63(48.8)$ & $7(4.1)$ & $17(10.1)$ & $89(52.7)$ \\
\hline Severe & $9(4.9)$ & $7(3.8)$ & $2(1.1)$ & $13(10.1)$ & $14(10.6)$ & $4(2.4)$ & $5(3.0)$ & $22(13.0)$ \\
\hline \multicolumn{9}{|l|}{ Associated symptoms } \\
\hline Nausea & $6(3.3)$ & $3(1.6)$ & $9(4.9)$ & $5(3.9)$ & $11(6.5)$ & $1(0.6)$ & $7(4.1)$ & $9(5.3)$ \\
\hline Belching & $5(2.7)$ & $3(1.6)$ & $6(3.3)$ & $3(2.30$ & $9(5.3)$ & $1(0.6)$ & $6(3.6)$ & $7(4.1)$ \\
\hline Bloating & 66 (35.9) & $45(24.5)$ & $9(4.9)$ & $30(23.2)$ & $86(50.9)$ & $11(6.5)$ & $18(10.7)$ & $41(24.3)$ \\
\hline Non-prominent reflux & 31 (16.8) & $18(9.8)$ & $5(2.7)$ & $28(21.7)$ & $25(14.8)$ & $15(8.9)$ & $2(1.2)$ & $42(24.9)$ \\
\hline
\end{tabular}

CI 3.41 to 12.94 ) (table 2). Subgroup analysis showed that it was associated with the three subgroups of FD: pure PDS (OR $5.90 ; 99.5 \%$ CI 2.53 to 14.66 ), pure EPS (OR $7.43 ; 99.5 \%$ CI 2.80 to 19.73 ) and overlap syndrome (OR 7.19; $99.5 \%$ CI 2.72 to 19.01 ) (table 3 ). Of the $141 \mathrm{FD}$ subjects with concomitant IBS (including 26 constipation-predominant, 42 diarrhoeapredominant, 30 mixed-type, and 43 un-subtyped), the proportions of subtypes of IBS in FD were similar $(p=0.25)$.

\section{DISCUSSION}

There are several novel findings in the present study. We found that PDS and EPS shared common risk factors, including younger age, NSAIDs consumption, anxiety and concomitant IBS. Interestingly, we identified several risk factors distinct for PDS but not EPS, including $H$. pylori infection(OR $1.8699 .5 \%$ CI 1.01 to 3.45 ), unmarried status (OR $4.2299 .5 \%$ CI 2.02 to 8.81), sleep disturbance (OR 2.56 99.5\% CI 1.29 to 5.07) and depression (OR $2.3499 .5 \%$ CI 1.04 to 5.36). Coffee consumption (OR $0.4999 .5 \%$ CI 0.25 to 0.92 ) was protective against PDS, but not EPS. We further showed that the association of H. pylori infection with PDS was probably mediated through the severity of gastric atrophy at the antrum. Interestingly, we also observed a higher prevalence of CagA positive $H$. pylori strains in PDS. These results collectively indicated that a distinct aetiopathogenesis underlies the subdivisions of FD according to the Rome III criteria.

The association of $H$. pylori with FD and its subgroups according to the Rome III criteria has been reported with inconsistent results in several observational studies. ${ }^{13} 1417$ Aro et al ${ }^{14}$ and Zagari et $a l^{17}$ found no significant association of H. pylori with FD in Western populations. Meta-analysis of randomised control trials revealed a small but significant reduction in dyspeptic symptoms after $H$. pylori eradication and the number needed to treat to cure was $14 .{ }^{11}{ }^{13}$ Of the six trials that addressed the differential impacts of $H$. pylori eradication on symptom relief according to subgroups of FD, ${ }^{12} 32-36$ only two studies applied the Rome III definition. ${ }^{12} 36$ Of the three trials that showed a benefit of $H$. pylori eradication on FD, there were no significant differences between subgroups. ${ }^{12} 3435$ By contrast, Lan $e t a l^{36}$ reported a significant effect only in the EPS subgroup. The contradictory results might result from differences in the definitions of subgroups, efficacies of eradication regimens, $H$. pylori infection prevalence and the ethnic groups. ${ }^{13}$ Further well designed randomised control trials are eagerly anticipated to assess whether therapeutic responses to H. pylori eradication differ according subgroups of FD.

There are several possible explanations for the different association of $H$. pylori infection with PDS and EPS. First, the higher prevalence of more virulent $H$. pylori strains in PDS might be contributory. This study found a higher prevalence of CagA positive $H$. pylori infection, which might account for more severe atrophic changes of the antrum, in patients with PDS. Second, the bacterial components and toxins of $H$. pylori infection might directly activate the peripheral sensory neurons and enhance the visceral hypersensitivity. This hypothesis was supported by a previous study which showed exaggerated postprandial gastric distension in $H$. pylori infected patients $(80 \%)$, as compared with uninfected patients (33\%). ${ }^{37}$ Although we found an association of $H$. pylori with PDS in a hospital-based study in Taiwan, where the prevalence of $H$. pylori infection and CagA positive strains remains high, a further populationbased study is warranted to estimate the relationship between $H$. pylori and FD in Asian populations.

The association of FD with psychopathology and personality traits has been reported in several studies. ${ }^{4}{ }^{16}$ However, randomised trials failed to demonstrate consistent beneficial effects of anxiolytic agents or antidepressants, probably related to its heterogeneous aetiopathogenesis. ${ }^{38}$ We found a significant association between depression and PDS, similar to the findings by Clauwaert et $a l^{39}$ and Handa et al. ${ }^{40}$ However, this was contradictory to a population-based study. ${ }^{14}$ We also observed a higher prevalence of sleep disturbance in PDS, but not in EPS. This result was consistent with previous hospital-based studies, but was not found in population-based research. ${ }^{41-43}$ By contrast, Yamawaki et al reported that sleep disturbance was similar in patients with EPS and those with PDS. ${ }^{44}$ These inconsistent findings might be attributed to differences in the study population (eg, hospital vs community, East vs West), assessment tools, 
Table 2 Risk factors of uninvestigated dyspepsia and functional dyspepsia as compared with healthy controls; multivariate analysis

\begin{tabular}{|c|c|c|c|c|c|c|c|}
\hline & \multirow{2}{*}{$\begin{array}{l}\text { No dyspepsia }(n=1031) \\
n(\%)\end{array}$} & \multicolumn{3}{|c|}{ Uninvestigated dyspepsia $(\mathrm{n}=771$ ) } & \multicolumn{3}{|c|}{ Functional dyspepsia $(n=491)$} \\
\hline & & n (\%) & OR $(99.5 \% \mathrm{Cl})$ & $\mathrm{p}$ Value & n (\%) & OR $(99.5 \% \mathrm{Cl})$ & $\mathrm{p}$ Value \\
\hline \multicolumn{8}{|l|}{ Demographic factors } \\
\hline \multicolumn{8}{|l|}{ Sex } \\
\hline Male & $515(50.0)$ & $302(39.2)$ & 1 & 0.008 & $146(29.7)$ & 1 & $<0.001$ \\
\hline Female & $516(50.0)$ & $469(60.8)$ & 1.52 (0.98 to 2.38$)$ & & $345(70.3)$ & 2.01 (1.16 to 3.47$)$ & \\
\hline \multicolumn{8}{|l|}{ Age (years) } \\
\hline Mean (SD) & $51.79(10.69)$ & $46(13.80)$ & $0.96(0.94$ to 0.98$)$ & $<0.001$ & $45.0(13.30)$ & 0.95 (0.93 to 0.98$)$ & $<0.001$ \\
\hline \multicolumn{8}{|l|}{ Occupation } \\
\hline Unemployed & $354(34.3)$ & $250(32.4)$ & 1 & 0.786 & $168(34.2)$ & 1 & 0.478 \\
\hline White-collar & $372(36.1)$ & $246(31.9)$ & 0.95 (0.61 to 1.49$)$ & 0.763 & $170(34.6)$ & 1.05 (0.63 to 1.75$)$ & 0.795 \\
\hline Labourer & $305(29.1)$ & $275(35.7)$ & 0.89 (0.55 to 1.43$)$ & 0.490 & $153(31.2)$ & $0.84(0.48$ to 1.47$)$ & 0.375 \\
\hline \multicolumn{8}{|l|}{ Married status } \\
\hline Married & $937(90.9)$ & $620(80.4)$ & 1 & 0.107 & $384(78.2)$ & 1 & 0.147 \\
\hline Never married & $94(9.1)$ & $151(19.6)$ & $1.42(0.77$ to 2.64$)$ & & $107(21.8)$ & $1.42(0.72$ to 2.80$)$ & \\
\hline \multicolumn{8}{|l|}{ Education level } \\
\hline Below elementary & $102(9.9)$ & $124(16.1)$ & 1 & & $60(12.2)$ & 1 & \\
\hline Below senior high school & $252(24.4)$ & $312(40.5)$ & $0.77(0.42$ to 1.41$)$ & 0.228 & $193(39.3)$ & 0.95 (0.46 to 1.97$)$ & 0.831 \\
\hline Above college & $677(65.7)$ & $335(43.5)$ & $0.32(0.17$ to 0.60$)$ & $<0.001$ & $238(48.5)$ & 0.42 (0.20 to 0.88$)$ & 0.001 \\
\hline \multicolumn{8}{|l|}{ Lifestyle factors } \\
\hline \multicolumn{8}{|l|}{ BMI $\left(\mathrm{kg} / \mathrm{m}^{2}\right)$} \\
\hline Mean (SD) & $23.52(3.19)$ & $23.72(7.63)$ & 1.02 (0.99 to 1.06$)$ & 0.081 & $22.94(5.10)$ & $1.00(0.95$ to 1.05$)$ & 0.872 \\
\hline \multicolumn{8}{|l|}{ Smoking } \\
\hline Never & $831(80.6)$ & $545(70.7)$ & 1 & 0.032 & 381 (77.6) & 1 & 0.284 \\
\hline Ever & $200(19.4)$ & $226(29.3)$ & $1.49(0.88$ to 2.51$)$ & & $110(22.4)$ & 1.28 (0.68 to 2.41$)$ & \\
\hline \multicolumn{8}{|l|}{ Alcohol consumption } \\
\hline Never & $842(81.7)$ & $558(72.4)$ & 1 & 0.063 & $378(77.0)$ & 1 & 0.216 \\
\hline Ever & $189(18.3)$ & $213(27.6)$ & $1.38(0.85$ to 2.24$)$ & & $113(23.0)$ & $1.29(0.73$ to 2.29$)$ & \\
\hline \multicolumn{8}{|l|}{ Betel nut chewing } \\
\hline Never & 1017 (98.6) & $683(88.6)$ & 1 & $<0.001$ & $452(92.1)$ & 1 & 0.001 \\
\hline Ever & $14(1.4)$ & $88(11.4)$ & 6.31 (2.20 to 18.12$)$ & & $39(7.9)$ & $4.55(1.30$ to 15.91$)$ & \\
\hline \multicolumn{8}{|l|}{ Tea consumption } \\
\hline Never & $461(44.7)$ & $383(49.7)$ & 1 & 0.302 & $247(50.3)$ & 1 & 0.213 \\
\hline Ever & $570(55.3)$ & $388(50.3)$ & 0.87 (0.59 to 1.28$)$ & & $244(49.7)$ & $0.82(0.52$ to 1.29$)$ & \\
\hline \multicolumn{8}{|l|}{ Coffee consumption } \\
\hline Never & $545(52.9)$ & $479(62.1)$ & 1 & 0.002 & $297(60.5)$ & 1 & 0.011 \\
\hline Ever & $486(47.1)$ & $292(37.9)$ & 0.65 (0.44 to 0.97$)$ & & $194(39.5)$ & $0.66(0.41$ to 1.04$)$ & \\
\hline Vegetarian & & & & & & & \\
\hline Never & $996(96.9)$ & 724 (93.9) & 1 & 0.106 & $462(94.1)$ & 1 & 0.319 \\
\hline Ever & $35(3.4)$ & $47(6.1)$ & 1.62 (0.70 to 3.73$)$ & & $29(5.9)$ & $1.41(0.53$ to 3.73$)$ & \\
\hline Exercise habit & & & & & & & \\
\hline Less/never & $361(35.0)$ & $488(63.3)$ & 1 & $<0.001$ & $297(60.5)$ & 1 & 0.012 \\
\hline Ever & $670(65.0)$ & $283(36.7)$ & 0.51 (0.35 to 0.74$)$ & & $194(39.5)$ & $0.68(0.44$ to 1.05$)$ & \\
\hline NSAIDs recent consumption & & & & & & & \\
\hline Never & $997(96.7)$ & 598 (77.6) & 1 & $<0.001$ & $383(78.0)$ & 1 & $<0.001$ \\
\hline Ever & $34(3.3)$ & $173(22.4)$ & 5.96 (3.04 to 11.69 ) & & $108(22.0)$ & 6.60 (3.13 to 13.90$)$ & \\
\hline Aspirin recent consumption & & & & & & & \\
\hline Never & $997(96.7)$ & $761(98.7)$ & 1 & 0.072 & $484(98.6)$ & 1 & 0.343 \\
\hline Ever & $34(3.3)$ & $10(1.3)$ & $0.43(0.11$ to 1.61$)$ & & $7(1.4)$ & 0.61 (0.14 to 2.68$)$ & \\
\hline Psychological factors (BSRS-5 & & & & & & & \\
\hline I. Sleep disturbance & & & & & & & \\
\hline No & $619(60.0)$ & $280(36.3)$ & 1 & $<0.001$ & $161(32.8)$ & 1 & 0.001 \\
\hline Yes & $412(40.0)$ & $491(63.7)$ & 1.76 (1.18 to 2.61$)$ & & $330(67.2)$ & 1.72 (1.09 to 2.73$)$ & \\
\hline II. Anxiety & & & & & & & \\
\hline No & $727(70.5)$ & 321 (41.6) & 1 & $<0.001$ & $169(34.4)$ & 1 & $<0.001$ \\
\hline Yes & $304(29.5)$ & $450(58.4)$ & $2.82(1.78$ to 4.46$)$ & & $332(64.8)$ & 3.41 (2.01 to 5.77$)$ & \\
\hline III. Hostility & & & & & & & \\
\hline No & $674(65.4)$ & $376(48.8)$ & 1 & 0.021 & $214(43.6)$ & 1 & 0.176 \\
\hline Yes & 357 (34.6) & $395(51.2)$ & 0.67 (0.41 to 1.09$)$ & & $277(56.4)$ & 0.76 (0.44 to 1.34$)$ & \\
\hline
\end{tabular}


Table 2 Continued

\begin{tabular}{|c|c|c|c|c|c|c|c|}
\hline & \multirow{2}{*}{$\begin{array}{l}\text { No dyspepsia }(n=1031) \\
n(\%)\end{array}$} & \multicolumn{3}{|c|}{ Uninvestigated dyspepsia $(\mathrm{n}=771)$} & \multicolumn{3}{|c|}{ Functional dyspepsia $(n=491)$} \\
\hline & & n (\%) & OR $(99.5 \% \mathrm{Cl})$ & p Value & n (\%) & OR $(99.5 \% \mathrm{Cl})$ & $p$ Value \\
\hline \multicolumn{8}{|c|}{ IV. Depression } \\
\hline No & $759(73.6)$ & $389(50.5)$ & 1 & 0.001 & $225(45.8)$ & 1 & 0.001 \\
\hline Yes & $272(26.4)$ & $382(49.5)$ & 1.80 (1.10 to 2.93$)$ & & $266(54.2)$ & $1.92(1.10$ to 3.33$)$ & \\
\hline \multicolumn{8}{|c|}{ V. Inferiority } \\
\hline No & $891(86.4)$ & $579(75.1)$ & 1 & 0.007 & $366(74.5)$ & 1 & 0.001 \\
\hline Yes & $140(13.6)$ & $192(24.9)$ & 0.59 (0.34 to 1.02 ) & & $125(25.5)$ & $0.48(0.26$ to 0.90$)$ & \\
\hline \multicolumn{8}{|c|}{ Other factors } \\
\hline \multicolumn{8}{|c|}{ H. pylori } \\
\hline No & $652(63.2)$ & $413(53.6)$ & 1 & $<0.001$ & $295(60.1)$ & 1 & 0.003 \\
\hline Yes & $379(36.8)$ & $358(46.4)$ & 1.88 (1.30 to 2.73$)$ & & $196(39.9)$ & 1.60 (1.03 to 2.48$)$ & \\
\hline \multicolumn{8}{|l|}{ IBS } \\
\hline No & $999(96.9)$ & $620(80.4)$ & 1 & $<0.001$ & $347(70.7)$ & 1 & $<0.001$ \\
\hline Yes & $32(3.1)$ & 151 (19.6) & 6.09 (3.12 to 11.91$)$ & & $144(29.3)$ & 6.89 (3.41 to 13.94$)$ & \\
\hline
\end{tabular}

and ethnic and cultural differences. Nevertheless, these studies collectively showed that subgroups of FD differ in the association with psychological stress.

The mechanism underpinning the link with psychopathology remains poorly understood, but there are several plausible explanations. Perturbation of brain-gut signalling, including impaired sensory filtering, impaired cognitive circuits, or impaired descending modulatory system to physiological and salient/noxious stimuli, might be impaired by psychosocial factors, which in turn leads to impaired descending modulatory pathways. ${ }^{16}$ Dysfunction of the autonomic nervous system, including hyperactive sympathetic tone and hypoactive vagal counterpart, ${ }^{45}$ might lead to visceral hypersensitivity and cause dyspeptic symptoms. Some pathophysiological studies reported that impaired gastric accommodation was more common in patients with PDS than those with EPS. ${ }^{4}$ Therefore, it is possible that the autonomic dysfunction associated with depression might impair gastric accommodation and produce symptoms of PDS. ${ }^{45}$ Nevertheless, the results from our study led us to propose the hypothesis that antidepressants might be more effective in the subgroup with PDS. Further interventional trials are eagerly anticipated to prove this hypothesis.

Recent studies showed that the Rome III criteria cannot distinguish patients with organic diseases from those with FD. ${ }^{46} 47$ Our study had similar results, reporting that 36.3\% (280/771) of cases of uninvestigated dyspepsia had structural lesions on OGD. More importantly, we also observed a significant overlap $(n=169,34.4 \%)$ among patients diagnosed with PDS and those with EPS. Whereas the EPS and PDS syndromes can be discriminated better in population-based studies, significant overlap was observed in hospital-based studies. ${ }^{4}$ This indicated that the proportion of overlap might increase with disease severity and it is important to clarify whether those with the overlap syndrome have distinct pathogenesis. By revealing the association with NSAIDs, anxiety and IBS, our study showed that the overlap syndrome shared similar risk factors with pure EPS and pure PDS.

The impact of NSAIDs consumption on the risk of FD remains controversial. Our result agreed with Aro et al ${ }^{14}$ that NSAIDs might influence the risk of FD and its subgroups. However, it has recently been shown that enteropathy can be detected by capsule endoscopy in $50-68 \%$ of NSAID users. ${ }^{48}$ Therefore, some patients with 'FD' who have recently taken NSAIDs may actually have enteral lesions that are not detected on OGD. Besides, we found an interesting association of betel nut chewing with FD and the overlap subgroup. Betel nut chewing is a unique culture in Asia and has been shown to be a causal factor of squamous cell carcinoma of the oral cavity, oropharynx and oesophagus. ${ }^{49}$ Interpretation of this association requires caution, particularly when the educational level is significantly lower in patients with FD. Since the habit of betel nut chewing is more common in blue-collar labourers than in whitecollar workers, it could be a surrogate marker indicating low socioeconomic status (SES). Nevertheless, the association remained significant after adjustment for education and occupation, both of which could also stand for the SES. Besides, the association was significant for pure EPS and overlap syndrome, but not for pure PDS, indicating that this association was not related to lower SES alone. Clearly, this finding warrants further study for confirmation. Whether the association is directly related to the noxious stimuli of betel nuts or secondary to perturbation in visceral hypersensitivity needs to be clarified in future studies. The interesting protective effect of coffee consumption in PDS was probably related to the accelerated gastric emptying time of coffee. ${ }^{50} 51$ However, interventional trials are necessary to prove this hypothesis. We did not find an association between tea and FD in the present study. However, future studies are warranted to assess whether different kinds of tea have different biological effects in the pathogenesis of FD.

The strengths of this study included a large sample size, comprehensive analysis of each risk factors and endoscopic examination in all participants. We also assessed H. pylori status, its virulence genotypes and histological changes to explore the pathogenesis in different subgroups of FD. Nevertheless, there were some limitations. First, this was a hospital-based study which cannot be representative of the general population. However, the aim of the study is to analyse the risk factors of FD and its subgroups rather than to report the prevalence in the general population. Second, histological examination was not done in healthy controls. Nevertheless, this limitation did not compromise the finding that gastric atrophy was more severe in PDS patients than their EPS counterparts. Third, H. pylori 
Table 3 Risk factors of subgroups of functional dyspepsia as compared with healthy controls; multivariate analysis

\begin{tabular}{|c|c|c|c|c|c|c|c|c|c|c|}
\hline & \multirow{2}{*}{$\begin{array}{l}\text { No dyspepsia }(n=1031) \\
n(\%)\end{array}$} & \multicolumn{3}{|c|}{ Pure PDS $(n=184)$} & \multicolumn{3}{|c|}{ Pure EPS $(n=129)$} & \multicolumn{3}{|c|}{ Pure overlap $(n=169)$} \\
\hline & & $\mathrm{n}(\%)$ & OR $(99.5 \% \mathrm{CI})$ & $p$ Value & $\mathrm{n}(\%)$ & OR $(99.5 \% \mathrm{Cl})$ & $\mathrm{p}$ Value & n (\%) & OR $(99.5 \% \mathrm{CI})$ & $p$ Value \\
\hline \multicolumn{11}{|l|}{ Demographic factors } \\
\hline \multicolumn{11}{|l|}{ Sex } \\
\hline Male & $515(50.0)$ & $55(29.9)$ & 1 & 0.011 & $41(31.8)$ & 1 & 0.009 & $47(27.8)$ & 1 & 0.011 \\
\hline Female & $516(50.0)$ & $129(70.1)$ & 2.08 (0.93 to 4.66$)$ & & $88(68.2)$ & 2.26 (0.94 to 5.44$)$ & & $122(72.2)$ & 2.35 (0.92 to 6.04$)$ & \\
\hline \multicolumn{11}{|l|}{ Age } \\
\hline Mean (SD) & $51.79(10.69)$ & $44(13.83)$ & 0.94 (0.91 to 0.97$)$ & $<0.001$ & $46(13.12)$ & 0.96 (0.93 to 1.00$)$ & 0.005 & $44(12.87)$ & 0.95 (0.91 to 0.98$)$ & $<0.001$ \\
\hline \multicolumn{11}{|l|}{ Occupation } \\
\hline Unemployed & 354 (34.3) & $55(29.9)$ & 1 & 0.229 & $39(30.2)$ & 1 & 0.043 & $72(42.6)$ & 1 & 0.415 \\
\hline White-collar & $372(36.1)$ & $74(40.2)$ & 1.48 (0.71 to 3.08$)$ & 0.139 & $46(35.7)$ & 0.54 (0.24 to 1.20$)$ & 0.031 & $46(27.2)$ & 1.45 (0.63 to 3.31$)$ & 0.211 \\
\hline Labourer & $305(29.1)$ & $55(29.9)$ & 1.03 (0.46 to 2.32$)$ & 0.929 & $44(34.1)$ & 0.52 (0.22 to 1.25$)$ & 0.037 & $51(30.2)$ & $1.39(0.403 .77)$ & 0.287 \\
\hline \multicolumn{11}{|l|}{ Married } \\
\hline Yes & $937(90.9)$ & $130(71.0)$ & 1 & $<0.001$ & $103(79.8)$ & 1 & 0.610 & $138(86.7)$ & 1 & 0.882 \\
\hline Never & $94(9.1)$ & $53(29.0)$ & $4.22(2.02$ to 8.81$)$ & & $20(15.5)$ & 1.23 (0.40 to 3.77$)$ & & $31(18.3)$ & $1.06(0.37$ to 3.02$)$ & \\
\hline \multicolumn{11}{|l|}{ Education } \\
\hline Below elementary & $102(9.9)$ & $18(9.8)$ & 1 & & $17(13.2)$ & 1 & & $23(13.6)$ & 1 & \\
\hline Below senior high school & $252(24.4)$ & $67(36.4)$ & $1.19(0.39$ to 3.60$)$ & 0.658 & $49(38.0)$ & 1.23 (0.37 to 4.09$)$ & 0.629 & $75(44.4)$ & $0.70(0.24$ to 2.02$)$ & 0.339 \\
\hline Above college & $677(65.7)$ & $99(53.8)$ & 0.51 (0.17 to 1.56$)$ & 0.092 & $63(48.8)$ & 0.61 (0.18 to 2.05$)$ & 0.250 & $71(42.0)$ & $0.22(0.07$ to 0.67$)$ & $<0.001$ \\
\hline \multicolumn{11}{|l|}{ Blood type* } \\
\hline A type & $264(25.6)$ & $44(26.3)$ & 1 & & $30(27.8)$ & 1 & & $46(31.5)$ & 1 & \\
\hline B type & $223(21.6)$ & $42(25.1)$ & 1.05 (0.45 to 2.46$)$ & 0.879 & $27(25.0)$ & 1.17 (0.46 to 2.97$)$ & 0.640 & $25(17.1)$ & $0.782(0.30$ to 2.24$)$ & 0.580 \\
\hline AB type & $56(5.4)$ & $15(9.0)$ & $1.68(0.50$ to 5.63$)$ & 0.230 & $5(4.6)$ & 1.53 (0.33 to 7.13$)$ & 0.438 & $22(15.1)$ & 3.79 (1.15 to 12.48$)$ & 0.002 \\
\hline 0 type & $435(42.2)$ & $66(39.5)$ & $0.75(0.36$ to 1.60$)$ & 0.290 & $46(42.6)$ & 0.91 (0.40 to 2.04$)$ & 0.738 & $53(36.3)$ & $0.88(0.39$ to 1.99$)$ & 0.663 \\
\hline \multicolumn{11}{|l|}{ Lifestyle factors } \\
\hline \multicolumn{11}{|l|}{ BMI $\left(\mathrm{kg} / \mathrm{m}^{2}\right)$} \\
\hline Mean (SD) & $23.52(3.19)$ & $22.55(3.60)$ & 0.98 (0.89 to 1.09$)$ & 0.633 & $23.83(7.63)$ & 1.04 (0.98 to 1.11$)$ & 0.081 & $22.74(4.02)$ & 0.95 (0.85 to 1.05$)$ & 0.134 \\
\hline \multicolumn{11}{|l|}{ Smoking } \\
\hline Never & 831 (80.6) & $144(78.3)$ & 1 & 0.731 & $105(81.4)$ & 1 & 0.679 & $124(73.4)$ & 1 & 0.057 \\
\hline Ever & $200(19.4)$ & $40(21.7)$ & 1.12 (0.44 to 2.86$)$ & & $24(18.6)$ & 0.85 (0.28 to 2.58$)$ & & $45(26.6)$ & $2.00(0.72$ to 5.56$)$ & \\
\hline \multicolumn{11}{|l|}{ Alcohol consumption } \\
\hline Never & $842(81.7)$ & $138(75.0)$ & 1 & 0.036 & $105(81.4)$ & 1 & 0.785 & $128(75.7)$ & 1 & 0.296 \\
\hline Ever & $189(18.3)$ & $46(25.0)$ & 1.80 (0.82 to 3.97$)$ & & 24 (18.6) & $1.10(0.42$ to 2.88$)$ & & $41(24.3)$ & 1.41 (0.56 to 3.52$)$ & \\
\hline \multicolumn{11}{|l|}{ Betel nut } \\
\hline Never & 1017 (98.6) & $174(94.6)$ & 1 & 0.313 & $120(93.0)$ & 1 & 0.010 & $150(88.8)$ & 1 & 0.001 \\
\hline Ever & $14(1.4)$ & $10(5.4)$ & $1.97(0.30$ to 12.86$)$ & & $9(7.0)$ & 5.92 (0.85 to 41.21$)$ & & $19(11.2)$ & 6.11 (1.24 to 30.22$)$ & \\
\hline \multicolumn{11}{|l|}{ Coffee } \\
\hline Never & $545(52.9)$ & $119(64.7)$ & 1 & 0.002 & $75(58.1)$ & 1 & 0.053 & $96(56.8)$ & 1 & 0.227 \\
\hline Ever & $486(47.1)$ & $65(35.3)$ & $0.49(0.25$ to 0.92$)$ & & $54(41.9)$ & 0.62 (0.30 to 1.24$)$ & & 73 (43.2) & 0.74 (0.37 to 1.49$)$ & \\
\hline \multicolumn{11}{|l|}{ Exercise habit } \\
\hline Less/never & $361(35.0)$ & $105(57.1)$ & 1 & 0.206 & $80(62.0)$ & 1 & 0.124 & $106(62.7)$ & 1 & 0.012 \\
\hline Ever & $670(65.0)$ & $79(42.9)$ & $0.76(0.41$ to 1.41$)$ & & $49(38.0)$ & $0.69(0.35$ to 1.36$)$ & & $63(37.3)$ & $0.54(0.27$ to 1.07$)$ & \\
\hline
\end{tabular}

Demographic factors

Sex Female

Mean (SD)

Labourer

Married

Never

ducation

Below senior high school

B typ

Lifestyle factors

$\left(\mathrm{kg} / \mathrm{m}^{2}\right)$

Smoking

Excise habit

Ever

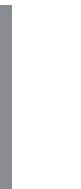




\section{Table 3 Continued}

\begin{tabular}{|c|c|c|c|c|c|c|c|c|c|c|}
\hline & \multirow{2}{*}{$\begin{array}{l}\text { No dyspepsia (n=1031) } \\
\mathrm{n}(\%)\end{array}$} & \multicolumn{3}{|c|}{ Pure PDS $(n=184)$} & \multicolumn{3}{|c|}{ Pure EPS ( $n=129)$} & \multicolumn{3}{|c|}{ Pure overlap $(n=169)$} \\
\hline & & n (\%) & OR $(99.5 \% \mathrm{Cl})$ & $\mathrm{p}$ Value & n (\%) & OR $(99.5 \% \mathrm{Cl})$ & $\mathrm{p}$ Value & n (\%) & OR $(99.5 \% \mathrm{Cl})$ & $\mathrm{p}$ Value \\
\hline \multicolumn{11}{|c|}{ NSAIDs recent used } \\
\hline Never & $997(96.7)$ & $151(82.1)$ & 1 & $<0.001$ & $99(76.4)$ & 1 & $<0.001$ & $125(74.0)$ & 1 & $<0.001$ \\
\hline Ever & $34(3.3)$ & $33(17.9)$ & $5.30(1.87$ to 15.05$)$ & & $30(23.3)$ & 7.62 (2.77 to 20.95$))$ & & $44(26.0)$ & 8.76 (3.28 to 23.40 ) & \\
\hline \multicolumn{11}{|c|}{ Psychological factors (BSRS-5) } \\
\hline \multicolumn{11}{|c|}{ I. Sleep disturbance } \\
\hline No & $619(60.0)$ & $47(25.5)$ & 1 & $<0.001$ & $72(55.8)$ & 1 & 0.221 & $39(23.1)$ & 1 & $<0.001$ \\
\hline Yes & $412(40.0)$ & $137(74.5))$ & 2.56 (1.29 to 5.07$)$ & & $57(44.2)$ & $0.73(0.35$ to 1.51$)$ & & $130(76.9)$ & $3.10(1.41$ to 6.81$)$ & \\
\hline \multicolumn{11}{|c|}{ II. Anxiety } \\
\hline No & $727(70.5)$ & $56(30.4)$ & 1 & $<0.001$ & $57(44.2)$ & 1 & 0.001 & $53(31.4)$ & 1 & $<0.001$ \\
\hline Yes & $304(29.5)$ & $128(69.6))$ & 2.80 (1.34 to 5.88$)$ & & $72(55.8)$ & 2.88 (1.21 to 6.79$)$ & & $116(68.6)$ & 4.36 (1.84 to 10.34$)$ & \\
\hline \multicolumn{11}{|c|}{ III. Hostility } \\
\hline No & $674(65.4)$ & $72(39.1)$ & 1 & 0.118 & $61(47.3)$ & 1 & 0.924 & $74(43.8)$ & 1 & 0.091 \\
\hline Yes & 357 (34.6) & $112(60.9))$ & $0.63(0.28$ to 1.44$)$ & & $68(52.7)$ & $1.03(0.41$ to 2.60$)$ & & $95(56.2)$ & $0.58(0.23$ to 1.48$)$ & \\
\hline \multicolumn{11}{|c|}{ IV. Depression } \\
\hline No & 759 (73.6) & $74(40.2)$ & 1 & 0.003 & $66(51.2)$ & 1 & 0.062 & $79(46.7)$ & 1 & 0.063 \\
\hline Yes & $272(26.4)$ & $110(59.8))$ & 2.34 (1.04 to 5.36$)$ & & $63(48.8)$ & $1.82(0.74$ to 4.49$)$ & & $90(53.3)$ & $1.81(0.74$ to 4.40$)$ & \\
\hline \multicolumn{11}{|c|}{ V. Inferiority } \\
\hline No & 891 (86.4) & $134(72.8))$ & 1 & 0.070 & $99(76.7)$ & 1 & 0.009 & $126(74.6)$ & 1 & 0.008 \\
\hline Yes & $140(13.6)$ & $50(27.2)$ & $0.58(0.24$ to 1.36$)$ & & $30(23.3)$ & $0.38(0.13$ to 1.08$)$ & & $43(25.4)$ & $0.40(0.15$ to 1.06$)$ & \\
\hline \multicolumn{11}{|c|}{ Other factors } \\
\hline \multicolumn{11}{|l|}{ H. pylori } \\
\hline No & 652 (63.2) & $102(55.4)$ & 1 & 0.005 & $77(59.7)$ & 1 & 0.148 & $110(65.1)$ & 1 & 0.646 \\
\hline Yes & $379(36.8)$ & $82(44.6)$ & 1.86 (1.01 to 3.45$)$ & & $50(40.3)$ & $1.43(0.72$ to 2.84$)$ & & $59(34.9)$ & $1.12(0.55$ to 2.28$)$ & \\
\hline \multicolumn{11}{|l|}{ IBS } \\
\hline No & 999 (96.9) & $129(70.1)$ & 1 & $<0.001$ & $96(74.4)$ & 1 & $<0.001$ & $116(68.6)$ & 1 & $<0.001$ \\
\hline Yes & $32(3.1)$ & $55(29.9)$ & 5.90 (2.53 to 14.66$)$ & & $33(25.6)$ & 7.43 (2.80 to 19.73$))$ & & $53(31.4)$ & $7.19(2.72$ to 19.01$)$ & \\
\hline
\end{tabular}

ORs and $99.5 \%$ Cls calculated using a multivariate logistic regression model adjusted for all variables of $p$ values less than 0.05 in the online supplementary table $\$ 2$ and multiple testing adjustment (Holm method).

*Blood type was unknown in 53 with control group, 17 with PDS, 23 with EPS, 25 with overlap syndrome.

BMI, body mass index; BSRS-5, 5-item Brief Symptom Rating Scale; EPS, epigastric pain syndrome; PDS, postprandial distress syndrome. 
$\square$ None $\square$ Mild $\square$ Moderate $\square$ Severe
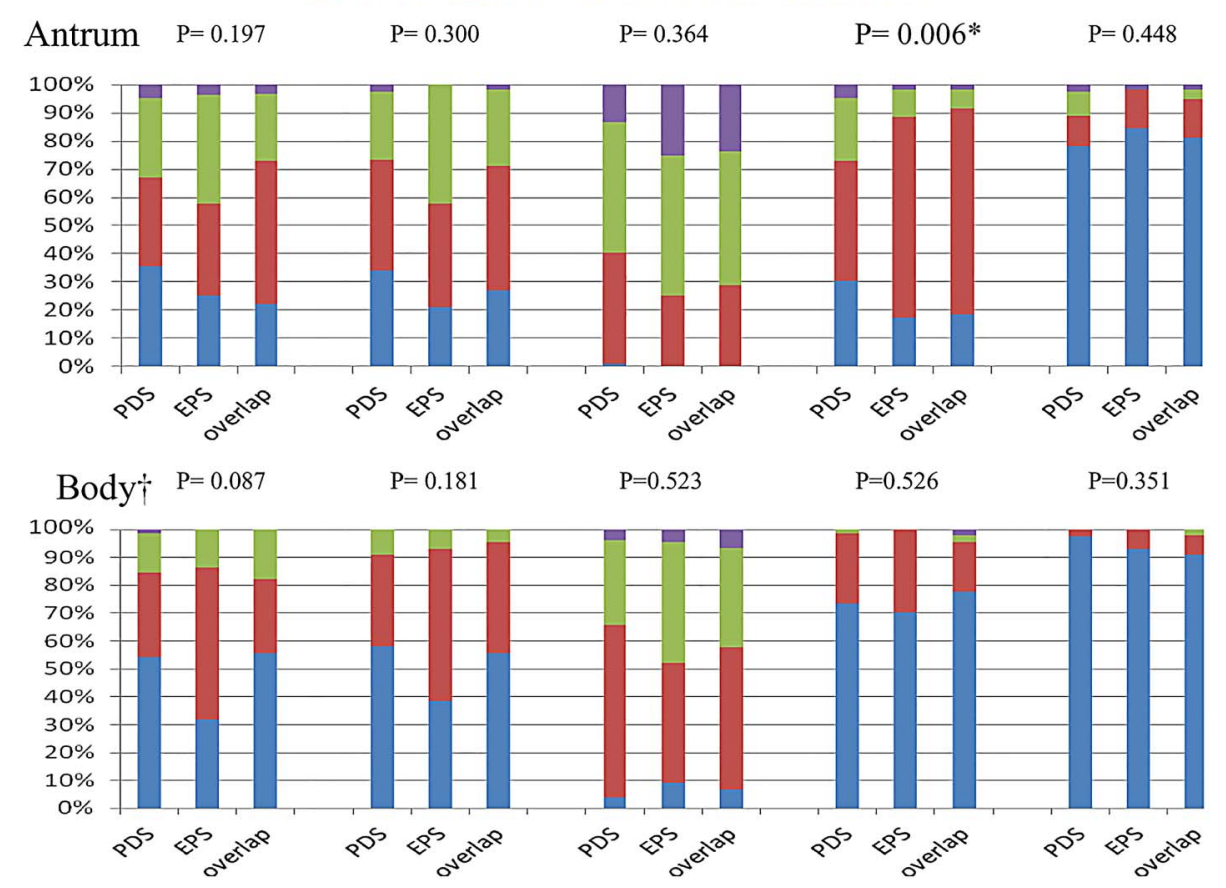

H.pylori Neutrophil Monocvte Atrophy Intestinal metaplasia

\section{H.pylori infected group}

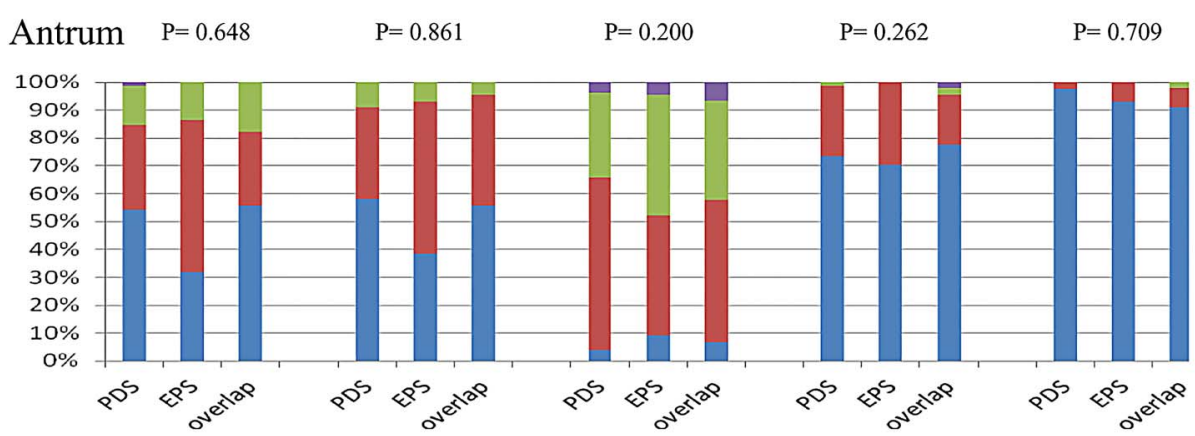
Body $\$ \quad \mathrm{P}=0.734$
$\mathrm{P}=0.479$
$\mathrm{P}=0.875$
$\mathrm{P}=0.716$
$\mathrm{P}=0.409$

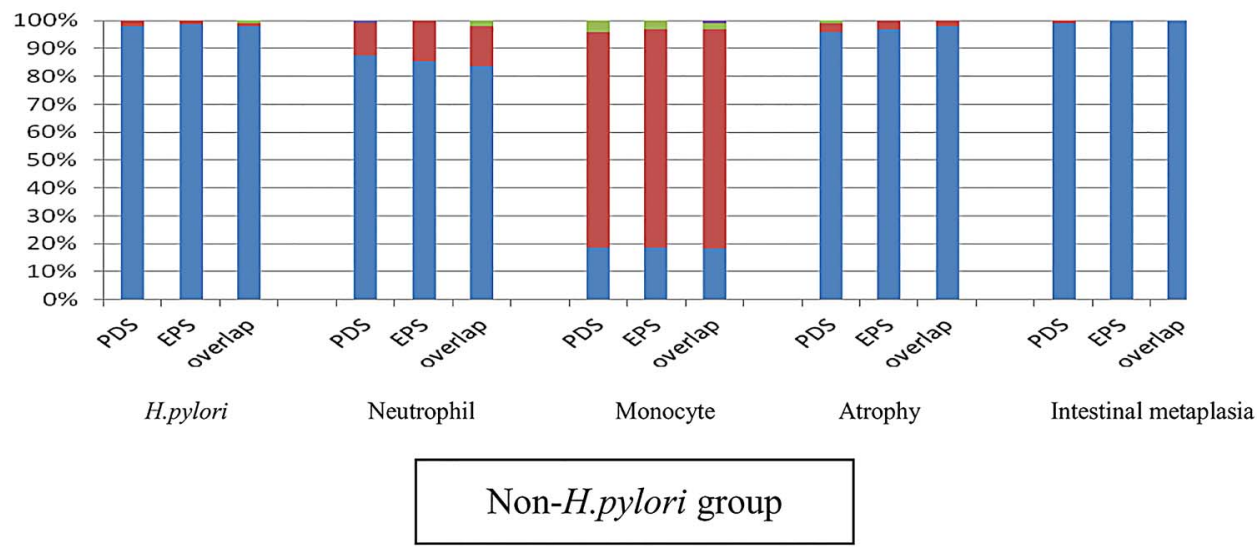

Figure 2 Severity of gastritis reported according to the Sydney classification. *Comparison among three distinct groups. $† H$. pylori infected group: Sydney classification of the body unknown in 25. ¥Non-H. pylori group: Sydney classification of the body unknown in 19. 
Table 4 Prevalence of virulence genotypes in subgroups of functional dyspepsia among $H$. pylori infected patients

\begin{tabular}{ccccc}
\hline & $\begin{array}{l}\text { Pure PDS } \\
\%(\mathbf{n})\end{array}$ & $\begin{array}{l}\text { Pure EPS } \\
\%(\mathbf{n})\end{array}$ & $\begin{array}{l}\text { Pure overlap } \\
\%(\mathbf{n})\end{array}$ & p Value \\
\hline CagA & & & & 0.044 \\
Positive & $98.4 \%(60 / 61)$ & $89.1 \%(41 / 46)$ & $85.7 \%(42 / 49)$ & \\
Negative & $1.6 \%(1 / 61)$ & $10.9 \%(5 / 46)$ & $14.3 \%(7 / 49)$ & \\
VacA & & & & 0.749 \\
S1 & $95.1 \%(58 / 61)$ & $97.9 \%(46 / 47)$ & $95.8 \%(46 / 48)$ & \\
S2 & $4.9 \%(3 / 61)$ & $2.1 \%(1 / 47)$ & $4.2 \%(2 / 48)$ & \\
VacA & & & & \\
M1 & $60.0 \%(36 / 60)$ & $45.5 \%(20 / 44)$ & $56.9 \%(29 / 51)$ & \\
M2 & $40.0 \%(24 / 60)$ & $54.5 \%(24 / 44)$ & $17.6 \%(9 / 51)$ & \\
\hline $\begin{array}{l}\text { p Values calculated using } \chi^{2} \text { test or Fisher's exact test as appropriate. } \\
\text { EPS, epigastric pain syndrome; PDS, postprandial distress syndrome. }\end{array}$ &
\end{tabular}

status was determined by UBT alone in healthy controls, whereas FD patients underwent rapid urease test, histological examination, culture and serology. However, ${ }^{13} \mathrm{C}$-UBT alone is accurate in the diagnosis of $H$. pylori infection. ${ }^{52}$ Another limitation was that income was not included in our analysis, although we did include occupation and education levels as markers of SES. In this study, we used the BSRS rather than HADs to quantify anxiety and depression, which might limit the comparability with other studies. However, we chose this instrument because it has been validated in our population. In this study, non-regular users who took NSAIDs/aspirin for less than 10 days in the month prior to enrolment were not excluded. Since NSAIDs/aspirin may also cause dyspepsia, patients who were taking NSAIDs/aspirin were excluded in some studies. However, patients taking NSAIDs/aspirin were not excluded in some population-based studies. ${ }^{14}{ }^{17}$ Therefore, we did not exclude those who took NSAIDs/aspirin for less than 10 days in the month prior to enrolment. Finally, this is a cross-sectional study which cannot establish causal relationships. Further cohort studies and interventional trials are anticipated to test the hypotheses generated from this study.

In conclusion, PDS and EPS shared some common risk factors, including younger age, NSAIDs consumption, anxiety and IBS. However, PDS, but not EPS, was associated with $H$. pylori and psychological stress, including sleep disturbance and depression. We further demonstrated that the different association of $H$. pylori with PDS was probably mediated through more severe gastric atrophy at the antrum and higher prevalence of CagA positive $H$. pylori infection. In addition, coffee consumption was protective against PDS but not EPS. Our results collectively implicate the presence of distinct aetiopathogenesis in the subdivisions of FD according to the Rome III criteria. Further randomised control trials are eagerly anticipated to test whether the therapeutic responses to $H$. pylori eradication and antidepressants differ according to the FD subgroup.

\footnotetext{
Author affiliations

${ }^{1}$ Department of Internal Medicine, National Taiwan University Hospital, Yun-Lin Branch, Douliou, Taiwan

${ }^{2}$ Department of Internal Medicine, National Taiwan University College of Medicine and National Taiwan University Hospital, Taipei, Taiwan

${ }^{3}$ Department of Internal Medicine, E-DA Hospital and I-Shou University, Kaohsiung County, Taiwan

${ }^{4}$ Division of Gastroenterology, Department of Internal Medicine, Mackay Memorial Hospital, Taipei, Taiwan

${ }^{5}$ Department of Internal Medicine, Kaohsiung Municipal Ta-Tung Hospital,

Kaohsiung Medical University, Kaohsiung, Taiwan
}

${ }^{6}$ Department of Medicine, National Yang-Ming University, School of Medicine, and Taipei Veterans General Hospital, Taipei, Taiwan

${ }^{7}$ School of Medicine, Fu Jen Catholic University, New Taipei City, Taiwan ${ }^{8}$ Department of Pathology, National Taiwan University Hospital, National Taiwan University College of Medicine, Taipei, Taiwan

Acknowledgements We would like to express our special thanks to the staff of the Eighth Core Lab, Department of Medical Research, National Taiwan University Hospital and the Bioinformatics Consortium of Taiwan, National Core Facility Program for Biotechnology (NSC 100-2319-B-010-002) for technical support in this study.

Contributors Study concept and design: Y-JF, J-ML, C-CC, M-SW; acquisition of data: Y-JF, J-ML, C-CC, J-YL, Y-CH, M-JC, P-HT, C-CC, C-YC, T-HY, W-HC, J-YW and J-CL; drafting of the manuscript: Y-JF and J-ML; critical revision of the manuscript for important intellectual content: M-SW; statistical analysis: Y-JF; study supervision: J-TL, C-TS, M-SW.

Funding The study was funded by the National Clinical Trial Center of National Taiwan University Hospital and the National Science Council, Executive Yuan, ROC, Taiwan (Grant Number: NSC 102-2325-B-002 -084).

Competing interests None.

\section{Patient consent Obtained.}

Ethics approval National Taiwan University Hospital.

Provenance and peer review Not commissioned; externally peer reviewed.

Open Access This is an Open Access article distributed in accordance with the Creative Commons Attribution Non Commercial (CC BY-NC 4.0) license, which permits others to distribute, remix, adapt, build upon this work non-commercially, and license their derivative works on different terms, provided the original work is properly cited and the use is non-commercial. See: http://creativecommons.org/ licenses/by-nc/4.0/

\section{REFERENCES}

1 Tack J, Talley NJ, Camilleri M, et al. Functional gastroduodenal disorders. Gastroenterology 2006;130:1466-79.

2 Ford AC, Moayyedi P. Dyspepsia. BMJ 2013;347:f5059.

3 Ghoshal UC, Singh R, Chang FY, et al. Functional Dyspepsia Consensus Team of the Asian Neurogastroenterology and Motility Association and the Asian Pacific Association of Gastroenterology. Epidemiology of uninvestigated and functional dyspepsia in Asia: facts and fiction. J Neurogastroenterol Motil 2011;17:235-44.

4 Tack J, Talley NJ. Functional dyspepsia-symptoms, definitions and validity of the Rome III criteria. Nat Rev Gastroenterol Hepatol 2013;10:134-41.

5 Agreus L, Borgquist L. The cost of gastro-oesophageal reflux disease, dyspepsia and peptic ulcer disease in Sweden. Pharmacoeconomics 2002;20:347-55.

6 Stanghellini V, Tosetti C, Paternico A, et al. Risk indicators of delayed gastric emptying of solids in patients with functional dyspepsia. Gastroenterology 1996;110:1036-42.

7 Tack J, Piessevaux $\mathrm{H}$, Coulie B, et al. Role of impaired gastric accommodation to a meal in functional dyspepsia. Gastroenterology 1998;115:1346-52.

8 Tack J, Caenepeel P, Fischler B, et al. Symptoms associated with hypersensitivity to gastric distention in functional dyspepsia. Gastroenterology 2001;121:526-35.

9 Vanheel $H$, Farré R. Changes in gastrointestinal tract function and structure in functional dyspepsia. Nat Rev Gastroenterol Hepatol 2013;10:142-9.

10 Moayyedi P, Feltbower R, Brown J, et al. Effect of population screening and treatment for Helicobacter pylori on dyspepsia and quality of life in the community: a randomised controlled trial. Leeds HELP Study Group. Lancet 2000;355:1665-9.

11 Moayyedi P, Soo S, Deeks J, et al. Eradication of Helicobacter pylori for non-ulcer dyspepsia. Cochrane Database Syst Rev 2006;2:CD002096.

12 Mazzoleni LE, Sander GB, Francesconi CF, et al. Helicobacter pylori Eradication in Functional Dyspepsia: HEROES Trial. Arch Intern Med 2011;171:1929-36.

13 Suzuki H, Moayyedi P. Helicobacter pylori infection in functional dyspepsia. Nat Rev Gastroenterol Hepatol 2013;10:168-74.

14 Aro P, Talley NJ, Ronkainen J, et al. Anxiety is associated with uninvestigated and functional dyspepsia (Rome III criteria) in a Swedish population-based study. Gastroenterology 2009;137:94-100.

15 Hsu YC, Liou JM, Liao SC, et al. Psychopathology and personality trait in subgroups of functional dyspepsia based on Rome III criteria. Am J Gastroenterol 2009;104:2534-42.

16 Van Oudenhove L, Aziz Q. The role of psychosocial factors and psychiatric disorders in functional dyspepsia. Nat Rev Gastroenterol Hepatol 2013;10:158-67.

17 Zagari RM, Law GR, Fuccio L, et al. Epidemiology of functional dyspepsia and subgroups in the Italian general population: an endoscopic study. Gastroenterology 2010;138:1302-11.

18 Mahadeva S, Yadav H, Rampal S, et al. Risk factors associated with dyspepsia in a rural Asian population and its impact on quality of life. Am J Gastroenterol 2010;105:904-12. 
19 Moayyedi P, Forman D, Braunholtz D, et al. The proportion of upper gastrointestinal symptoms in the community associated with Helicobacter pylori, lifestyle factors, and nonsteroidal anti-inflammatory drugs. Leeds HELP Study Group. Am J Gastroenterol 2000;95:1448-55.

20 Feinle-Bisset C, Azpiroz F. Dietary and lifestyle factors in functional dyspepsia. Nat Rev Gastroenterol Hepatol 2013;10:150-7.

21 Camilleri M, Stanghellini V. Current management strategies and emerging treatments for functional dyspepsia. Nat Rev Gastroenterol Hepatol 2013;10:187-94.

22 Miwa $\mathrm{H}$, Ghoshal UC, Fock KM, et al. Asian consensus report on functional dyspepsia. J Gastroenterol Hepatol 2012;27:626-41.

23 Futagami S, Shindo T, Kawagoe T, et al. Migration of eosinophils and CCR2-I CD68-double positive cells into the duodenal mucosa of patients with postinfectious functional dyspepsia. Am J Gastroenterol 2010;105:1835-42.

24 Talley NJ, Walker MM, Aro P, et al. Non-ulcer dyspepsia and duodenal eosinophilia: an adult endoscopic population-based case-control study. Clin Gastroenterol Hepatol 2007:5:1175-83.

25 Shindo T, Futagami S, Hiratsuka T, et al. Comparison of gastric emptying and plasma ghrelin levels in patients with functional dyspepsia and non-erosive reflux disease. Digestion 2009;79:65-72.

26 Haag S, Senf W, Tagay S, et al. Is there any association between disturbed gastrointestinal visceromotor and sensory function and impaired quality of life in functional dyspepsia? Neurogastroenterol Motil 2010;22:262-e79.

27 Kusano M, Zai H, Shimoyama Y, et al. Rapid gastric emptying, rather than delayed gastric emptying, might provoke functional dyspepsia. J Gastroenterol Hepatol 2011;26(Suppl 3):75-8.

28 Turkkan E, Uslan I, Acarturk G, et al. Does Helicobacter pylori-induced inflammation of gastric mucosa determine the severity of symptoms in functional dyspepsia? J Gastroenterol 2009;44:66-70.

29 Hsu YC, Liou JM, Yang TH, et al. Proton pump inhibitor versus prokinetic therapy in patients with functional dyspepsia: is therapeutic response predicted by Rome III subgroups? J Gastroenterol 2011;46:183-90.

30 Lee MB, Liao SC, Lee YJ, et al. Development and verification of validity and reliability of a short screening instrument to identify psychiatric morbidity. J Formos Med Assoc 2003;102:687-94.

31 Liou JM, Chen CC, Chang CY, et al. Efficacy of genotypic resistance-guided sequential therapy in the third-line treatment of refractory Helicobacter pylori infection: a multicentre clinical trial. J Antimicrob Chemother 2013;68:450-6.

$32 \mathrm{Hsu} \mathrm{PI}$, Lai KH, Tseng HH, et al. Eradication of Helicobacter pylori prevents ulcer development in patients with ulcer-like functional dyspepsia. Aliment Pharmacol Ther 2001;15:195-201.

33 Talley NJ, Janssens J, Lauritsen K, et al. Eradication of Helicobacter pylori in functional dyspepsia: randomised double blind placebo controlled trial with 12 months' follow up. The Optimal Regimen Cures Helicobacter Induced Dyspepsia (ORCHID) Study Group. BMJ 1999;318:833-7.

34 Gwee KA, Teng L, Wong RK, et al. The response of Asian patients with functional dyspepsia to eradication of Helicobacter pylori infection. Eur J Gastroenterol Hepatol 2009:21:417-24.
35 Bruley Des Varannes S, Fléjou JF, Colin R, et al. There are some benefits for eradicating Helicobacter pylori in patients with non-ulcer dyspepsia. Aliment Pharmacol Ther 2001;15:1177-85.

36 Lan L, Yu J, Chen YL, et al. Symptom-based tendencies of Helicobacter pylori eradication in patients with functional dyspepsia. World J Gastroenterol 2011;17:3242-7.

37 Thumshirn M, Camilleri M, Saslow SB, et al. Gastric accommodation in non-ulcer dyspepsia and the roles of Helicobacter pylori infection and vagal function. Gut 1999:44:55-64.

38 Hojo M, Miwa H, Yokoyama T, et al. Treatment of functional dyspepsia with antianxiety or antidepressive agents: systematic review. J Gastroenterol 2005;40:1036-42.

39 Clauwaert $N$, Jones MP, Holvoet $L$, et al. Associations between gastric sensorimotor function, depression, somatization, and symptom-based subgroups in functional gastroduodenal disorders: are all symptoms equal? Neurogastroenterol Motil 2012;24:1088-e565.

40 Handa M, Mine K, Yamamoto $H$, et al. Esophageal motility and psychiatric factors in functional dyspepsia patients with or without pain. Dig Dis Sci 1999;44:2094-8.

41 Lacy BE, Everhart $K$, Crowell MD. Functional dyspepsia is associated with sleep disorders. Clin Gastroenterol Hepatol 2011;9:410-14.

42 Vege SS, Locke GR III, Weaver AL, et al. Functional gastrointestinal disorders among people with sleep disturbances: a population-based study. Mayo Clin Proc 2004;79:1501-6.

43 Yamawaki H, Futagami S, Shimpuku M, et al. Impact of sleep disorders, quality of life and gastric emptying in distinct subtypes of functional dyspepsia in Japan. J Neurogastroenterol Motil 2014;20:104-12.

44 Friedman $\mathrm{BH}$. An autonomic flexibility-neurovisceral integration model of anxiety and cardiac vagal tone. Biol Psychol 2007;74:185-99.

45 Carney RM, Freedland KE, Veith RC. Depression, the autonomic nervous system, and coronary heart disease. Psychosom Med 2005;67(Suppl 1):S29-33.

46 Xiao YL, Peng S, Tao J, et al. Prevalence and symptom pattern of pathologic esophageal acid reflux in patients with functional dyspepsia based on the Rome III criteria. Am J Gastroenterol 2010;105:2626-31.

47 Ford AC, Bercik P, Morgan DG, et al. The Rome III Criteria for the Diagnosis of Functional Dyspepsia in Secondary Care Are Not Superior to Previous Definitions. Gastroenterology 2014;146:932-40.e1.

48 Maiden L. Capsule endoscopic diagnosis of nonsteroidal antiinflammatory drug-induced enteropathy. J Gastroenterol 2009;44(Suppl 19):64-71.

49 Akhtar S. Areca nut chewing and esophageal squamous-cell carcinoma risk in Asians: a meta-analysis of case-control studies. Cancer Causes Control 2013:24:257-65.

50 Akimoto $\mathrm{K}$, Inamori $\mathrm{M}$, lida $\mathrm{H}$, et al. Does postprandial coffee intake enhance gastric emptying?: a crossover study using continuous real time $13 \mathrm{C}$ breath test (BreathID system). Hepatogastroenterology 2009;56:918-20.

51 Lien HC, Chen GH, Chang CS, et al. The effect of coffee on gastric emptying. Nucl Med Commun 1995;16:923-6.

52 Malfertheiner P, Megraud F, O'Morain CA, et al. Management of Helicobacter pylori infection-the Maastricht IV/ Florence Consensus Report. Gut 2012;61:646-64. 